to Shurdin Gornpa, in lat. $29^{\circ} 30^{\prime} \mathrm{N}$., long. $97^{\circ} 0^{\prime} \mathrm{E}$., where a base camp will be established at $13,600 \mathrm{ft}$. altitude. From here the collecting work will be done. This is the cross-roads of Asia, the meeting place of four floral regions, the Central Asian, Sino-Himalayan, Indo-Malayan, and Eastern Asiatic ; and it harbours the richest alpine flora in the world. The flora of this area should in fact throw light on both the earlier east and west distribution of plants across south-eastern Asia, and on the later north and south distribution, down the Malay Peninsula, brought about during the last glacial epoch. The predominance of the former is difficult to account for if we assume the Himalayan uplift to stop short at the Tsangpo bend, or to curve southwards at this point. On the other hand, if the Himalayan axis is prolonged eastwards, the Salween River must cut across it in a very deep gorge, and should moreover cross at a point of maximum elevation, precisely as the Indus and Tsangpo do. These are matters for investigation. Thus both botanical and geographical work will be done. These are closely related, and each illuminates the other. The botanical collecting will be done on behalf of the Department of Botany of the British Museum.

\section{Weather Information to Aviators in India}

THE India Meteorological Department has set out a complete account of the arrangements in force for the supply of reports on existing weather and of anticipated weather to aviators flying over any part of an immense area which includes not only India but also the Persian Gulf coast east of Bushire, Baluchistan and Burma (India Meteorological Department. Meteorological Organisation in India for the Supply of Weather Information to Aviators. Pp. iii + 27. (Calcutta : Government of India Central Publication Branch, 1932.) 12 annas ; 1s. 3d.) There are five main forecasting centres, at Karachi, Calcutta, Poona, Peshawar and Quetta. The first three centres are organised with a view of issuing reports and forecasts to civil aviators, and the last two deal mainly with the requirements of the R.A.F. The local centres also number five, namely Rangoon, Akyab, Dum Dum, Allahabad and Jodhpur. There would normally be available at such local centres information about the force and direction of the wind up to a height of 10,000 feet. There is another type of distributing centre-the pilot balloon station-of which there is a relatively large number. These are aerodromes or landing grounds with observers who make soundings of the upper atmosphere with pilot balloons, and are able to supply the information about upper winds so obtained to aviators on request, and presumably are also largely responsible for supplying such local information on this subject as is required at the more important centres. The information given in this pamphlet appears to include everything that can possibly be required by aviators, including the times of issue of the regular broadcasts, all necessary codes, and the wave-lengths, together with detailed instructions as to the procedure for obtaining special reports while in flight.

\section{Galvanometer Mirrors for Sound Recording}

Is the variable width method of recording sound on film, a galvanometer is used in which a loop of metal ribbon, $0 \cdot 005 \mathrm{in}$. broad and $0.0005 \mathrm{in}$. thick, is placed between the poles of a permanent magnet, a small mirror being cemented across the two arms of the loop. When speech currents from the microphone and amplifiers pass along the ribbon, the mirror vibrates and causes the reflected beam of light to traverse a narrow slit at right angles to the direction of motion of the film, and thus trace a graph of the sound waves. Since the upper limit of reproduction from the ordinary talking film projection apparatus is about 6000 cycles per second, the natural frequency of oscillation of the galvanometer must be at least as great as this. The inertia of its moving parts must, therefore, be low. The mirror must be as light and small as possible. It should also be accurately surfaced and silvered in order to ensure uniform reflection. The production of such mirrors is an interesting piece of optical work involving manipulative processes on a different scale from that employed for the usual products of the manufacturing optician. Mirrors made by Messrs. Taylor, Taylor and Hobson, Ltd., Stoughton Street Works, Leicester, specially suitable for these galvanometers, are rectangular in shape and measure $0.032 \mathrm{in}$. by $0.018 \mathrm{in}$. by $0.004 \mathrm{in}$. The glass from which they are made is first cut to the correct size and then optically worked on both sides. The back surface is silvered by cathode sputtering and is protected by a suitable varnish. The finished mirror weighs $0.0001 \mathrm{gm}$.

\section{Memorial to Laplace}

$L$ 'Astronomie for September contains a panegyric on Laplace, delivered by Dr. E. Esclangon, director of the Paris Observatory, on the occasion of the unveiling of a statue of the famous astronomer at Beaumont-en-Auge on July 3. Dr. Esclangon observes that Laplace is justly called the French Newton; while basing his work on Newton's law of universal gravitation, he carried the results of this law very much further than any of his predecessors. Special mention is made of his detection of the cause of the lunar acceleration arising from the diminution of the eccentricity of the earth's orbit. He also made useful researches on the theory of the tides; and his famous nebular hypothesis, though no longer held in its original form, at least as regards the solar system, was a valuable contribution to cosmogony, and formed the starting-point of many other theories.

\section{Reversion in a Hybrid Macaw}

WHAT appears like a very striking case of reversion in a species-hybrid is related, in the Avicultural Magazine for September, p. 220, by A. Anderson, who describes a hybrid macaw bird in New Zealand this year between a male of the red-and-yellow and a female of the blue-and-yellow species. As one parent is red and the other yellow below, it is not surprising that the hybrid young bird shows both 